\title{
Escuta de Famílias em Domicílio: Ação do Psicólogo na Estratégia de Saúde
}

Listening To Families In Domicile: The Action Of Psychologists In Homes Attended By The

Family Health Strategy

Escucha De Familias En Domicilio: Acción Del Psicólogo En La Estrategia De Salud
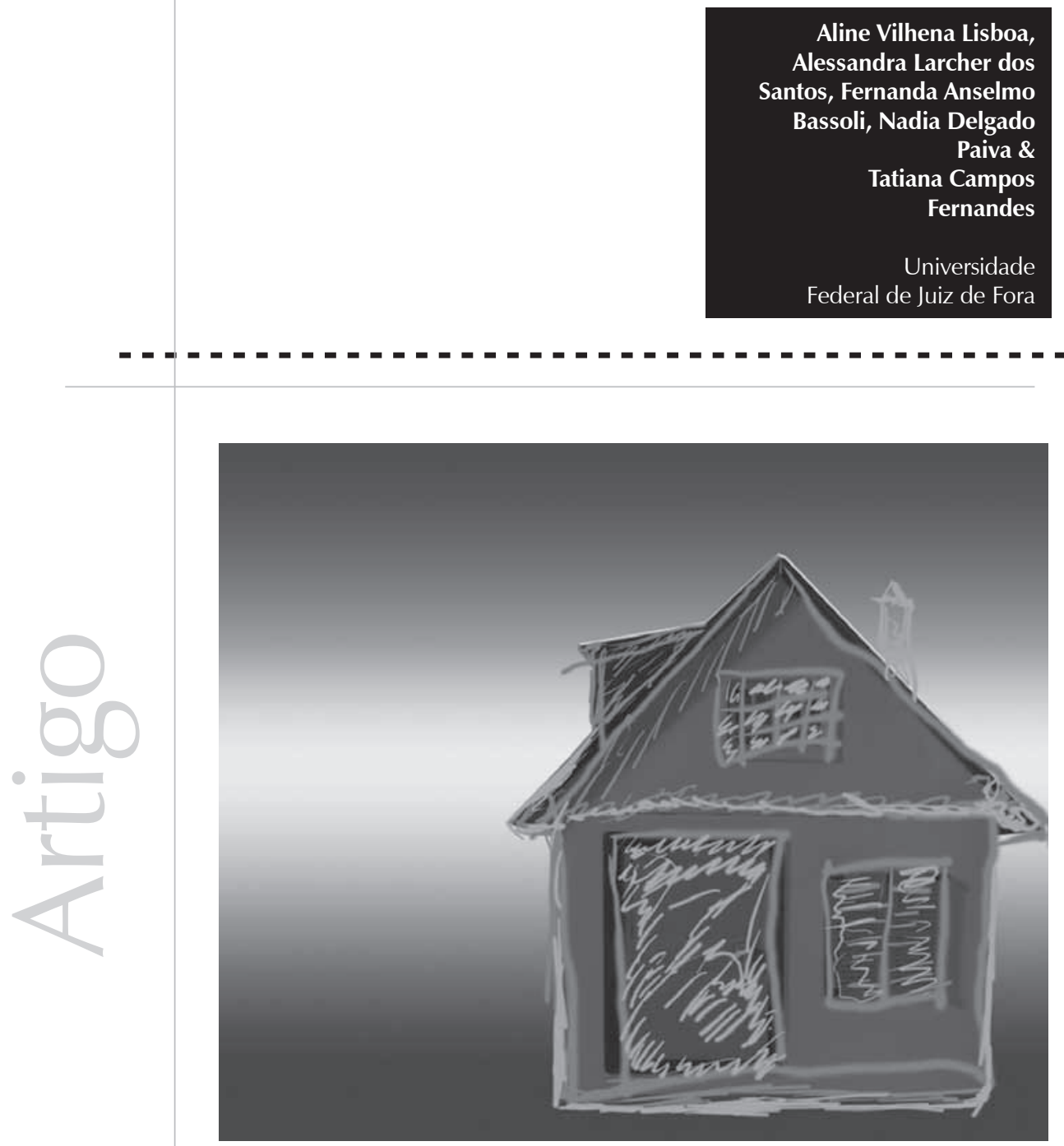
Resumo: Este trabalho relata a experiência da ação do psicólogo em uma pesquisa de doutorado, que vem contribuir para a atenção básica com famílias em domicílio. A pesquisa foi desenvolvida em uma unidade básica de saúde de uma cidade do interior de Minas Gerais. Com base na fundamentação teórica sobre atenção básica, família e saúde, observa-se que uma das maiores dificuldades de adesão e de envolvimento de pacientes na Estratégia de Saúde da Família se deve a problemas familiares do ponto de vista psicológico. Assim, este relato mostra um caminho interdisciplinar para a atuação do psicólogo na unidade básica, aproximando o profissional de saúde da realidade funcional e cultural da família. O procedimento da pesquisa baseou-se em uma investigação qualitativa de campo com entrevistas semidirigidas realizadas em domicílios. Foram entrevistadas 14 famílias procurando-se compreender a sua história e dinâmica, a fim de contribuir para o redirecionamento de intervenções com a equipe de saúde. A partir da análise de conteúdo, destacamos a violência e o alcoolismo como alguns fatores que interferem na qualidade de vida da família e na relação família-equipe de saúde. Propomos algumas sugestões para o redirecionamento das ações da equipe.

Palavras-chave: Saúde da família. Atenção à saúde. Ação. Psicólogo.

\begin{abstract}
This paper reports the experience of a psychologist in her doctorate research, and it aims to contribute with the Primary Health Care, mainly in the action with families in homes. It was developed in a basic health unit of a small city of Minas Gerais. Based on the theoretical grounding of Primary Health Care, family and health, it was observed that the major problem to the involvement of patients in the Family Health Strategy was family problems, mainly from a psychological viewpoint. Thus, this paper shows an interdisciplinary way to the psychologist work in basic health units, approaching health professionals to the functional and cultural reality of the families. This is a qualitative research, conducted in households, with semistructured interviews. 14 families were interviewed, and this work intends to understand the history and the dynamics of the family, in order to contribute to the redirection of new interventions made by the health team. From the content analysis, it was highlighted that violence and alcoholism are the factors that more affect the family quality of life and the relationship family-health team. We make some suggestions to redirect the actions of the family-health team.
\end{abstract}

Keywords: Family health. Health care. Acting out (Psychology). Psychologist

Resumen: Este trabajo relata la experiencia de la acción del psicólogo en una investigación de doctorado, que viene a contribuir para la atención básica, con familias en domicilio. La investigación ha sido desarrollada en una unidad básica de salud de una ciudad interior de Minas Gerais. Con base en la fundamentación teórica sobre atención básica, familia y salud, se observa que una de las mayores dificultades de adhesión y de la participación de pacientes en la Estrategia de Salud de la Familia se debe a problemas familiares desde el punto de vista psicológico. De esa manera, este relato demuestra un camino interdisciplinario para la actuación del psicólogo en la unidad básica, acercando al profesional de salud a la realidad funcional y cultural de la familia. El procedimiento de la investigación se ha basado en una investigación cualitativa de campo con entrevistas semidirigidas llevadas a cabo en domicilios. Han sido entrevistadas 14 familias, buscándose comprender la historia y la dinámica, a fin de contribuir para el redireccionamiento de nuevas intervenciones con el equipo de salud. A partir del análisis de contenido, destacamos la violencia y el alcoholismo como algunos factores que interfieren en la calidad de vida de la familia y en la relación familiaequipo de salud. Proponemos algunas sugerencias para el redireccionamiento de las acciones del equipo. Palabras clave: Salud de la familia. Atención a la salud. Acción. Psicólogo.

Há mais de 40 anos no Brasil, a Psicologia vem fundamentando suas ações na compreensão da singularidade e das relações do sujeito com o meio. Como uma das principais ciências Pesquisa financiada pela CAPES, desenvolvida em parceria com uma unidade de atenção primária à saúde de uma cidade do interior de Minas Gerais e com uma universidade pública federal durante os anos 2007, 2008, 2009 e 2010. do mundo contemporâneo, as teorias e as práticas psicológicas estão estreitando diálogos clínicos e sociais, que procuram atender às novas e às velhas demandas do sofrimento humano.

Diante de vários campos de atuação do psicólogo, viemos apresentar o retrato da
Psicologia clínica ao alcance do social no contexto da atenção básica à saúde da família. Este relato de experiência pretende evidenciar a ação do psicólogo com famílias na atenção básica, uma vez que seu olhar clínico visualiza um caminho que acrescenta à saúde mais uma ação técnica e interdisciplinar. O trabalho clínico vem aproximar cada vez mais o profissional de saúde às particularidades do funcionamento, do cotidiano, da história e da cultura de uma família. 
Este trabalho compreende o relato de uma experiência obtida pelo pesquisador e por estagiários do curso de Psicologia durante o procedimento utilizado na pesquisa Atenção à saúde da família: estudo do processo de adoecimento no grupo ${ }^{1}$, cujo objetivo geral era investigar o adoecimento na família a partir das relações psicodinâmicas e das heranças transmitidas ao longo das gerações. Assim, são relatados os procedimentos realizados com famílias visitadas em domicílio, já que a intenção é apresentar a contribuição do trabalho do psicólogo para a equipe de Estratégia de Saúde da Família.

No contexto da saúde pública e na atenção básica, são observadas dificuldades por parte dos profissionais no trato com famílias, o que favorece desencontros e barreiras no tratamento e no acompanhamento dos usuários. É o que afirma Chazan (2004) em sua pesquisa, mostrando que uma das maiores dificuldades de adesão e de envolvimento de pacientes no tratamento pelas Estratégias de Saúde da Família está nos problemas familiares do ponto de vista psicológico. Nesse sentido, deve-se considerar a família um grupo com característica própria e coadjuvante na configuração da subjetividade e da construção do processo saúde/doença do sujeito, pois, antes de tudo, este carrega consigo lembranças, aprendizagens e heranças da família de origem.

Outras pesquisas revelam que uma das maiores questões sobre a eficácia do tratamento de um paciente está na qualidade das relações entre os membros familiares, como nos trabalhos de Bittencourt e Matheus, (2006), Castiel (1994), Cardoso, (2002, 2007) e Lisboa e Féres-Carneiro (2005). Pesquisas de Mello Filho e Burn (2004), que envolvem a família de pacientes portadores de doenças como a obesidade, o diabetes mellitus, a hipertensão, a cardiopatia, a renal crônica e os diferentes tipos de câncer, apontam características próprias de um relacionamento mais simbiótico, estressado, com conflitos conjugais, parentais, problemas financeiros e sociais.

Acredita-se que o olhar do psicólogo sobre a saúde da família oportuniza não só maior entendimento das doenças pelos usuários como da relação dos mesmos com suas famílias e profissionais de saúde. O trabalho desse profissional vem consolidar a relevante contribuição de sua ação técnica e interdisciplinar nas dificuldades e nas limitações da relação usuário-doença-família e profissional-usuário-família e facilitar as intervenções e os tratamentos pela equipe de saúde. A partir dessa questão, apresentamos alguns dados satisfatórios sobre a relação família e equipe de saúde a partir da escuta do psicólogo em domicílio. Este relato parte de uma pesquisa de campo, cujo procedimento foi embasado em uma investigação qualitativa, sendo utilizadas entrevistas semidirigidas com famílias em seu ambiente domiciliar. Todo o trabalho foi desenvolvido em uma unidade básica de saúde de uma cidade da região da zona da mata de Minas Gerais.

A seguir, apresentam-se breves fundamentações sobre o aspecto da atenção básica nos cuidados com a saúde para que se possa justificar o lugar do psicólogo no programa e na atenção básica, a contribuição da Psicologia e dos estudiosos de família para o cenário da saúde a partir da concepção de saúde e de família e o procedimento do psicólogo e dos estagiários de Psicologia junto às famílias e profissionais da ESF.

\section{Do modelo assistencial à atenção básica: as transformações dos cuidados com a saúde} Conforme retrospectiva histórica do período anterior ao PSF das autoras Santana e Carmagnami (2001) e as considerações de Viana e Dal Poz (2005), o início do SUS se deu com a implementação da Constituição Federal do Brasil, que apresenta uma nova organização para a saúde pública no País, 
pois nela foram definidos os princípios da universalidade, da descentralização e da organização de serviços. Desse modo, o SUS passa a ter uma proposta de reorganização do modelo de atenção à saúde, referenciado na perspectiva da atenção básica, integrando a assistência curativa com a prevenção e a promoção de saúde. O órgão assume ainda o compromisso de saúde como direito do cidadão e como recurso que apoia o desenvolvimento individual e coletivo, incentivando maior participação popular através da gestão participativa das políticas de saúde.

Mais tarde, a Lei no 8080, de 1990, regulamenta as novas ações e serviços de saúde, reorganizando as políticas de atenção básica. Essa reorganização se consolida pelo desafio de construir redes assistenciais eficazes e resolutivas em atenção básica, integralmente coesa com os níveis de atenção mais complexos, a qual prevê o desenvolvimento de mecanismos para a garantia de qualidade. Então, eis que surge o Programa Saúde da Família (PSF), em 1994, como principal estratégia para reestruturar a atenção básica no Brasil (Brasil, 1994; Viana \& Del Poz, 2005).

A história do PSF teve início quando o Ministério da Saúde formulou o Programa de Agentes Comunitários de Saúde - PACS, em 1991, tendo sido consolidado com a Portaria no 1886, de 1997, que regulamenta, implementa e operacionaliza o PAC e o PSF. A partir daí, enfocou-se a família como unidade de ação programática de saúde e não mais, ou tão somente, o indivíduo. O PSF significa uma nova dinâmica no estabelecimento de bases para os serviços e as ações de saúde, reorganizando a prática da atenção de forma mais integrada e racional ao utilizar os níveis de maior complexidade assistencial para garantir impacto favorável aos indicadores de saúde da população assistida e levar a saúde para mais perto da família (Brasil, 1997; Viana \& Dal Poz, 2005).
Os princípios gerais da Política Nacional de Atenção Básica (Brasil, 2006), contidos nas atuais Estratégias de Saúde da Família, se caracterizam por um conjunto de ações de saúde, no âmbito individual e coletivo, que abrangem a promoção e a proteção da saúde, a prevenção de agravos, o diagnóstico, o tratamento, a reabilitação e a manutenção da saúde. Como tema bastante fomentado, a atenção básica é desenvolvida através do exercício de práticas gerenciais e sanitárias democráticas e participativas, sob forma de trabalho em equipe. Implantá-la significa substituir as práticas tradicionais de assistência, com foco nas doenças, por um novo processo de trabalho comprometido com a elevação da qualidade de vida da população. Sendo assim, considera-se a saúde como condição que exige constante educação, reflexão e acompanhamento longitudinal interdisciplinar, enfim, ações que visem não somente à utilização de instrumentos técnicos de ponta mas também à mudança nos procedimentos enrijecidos pelas especializadas conferidas a cada área do conhecimento.

A saúde no Brasil sempre foi marcada por um modelo assistencial centrado na doença, que concentrava ações pontuais e desordenadas para o tratamento ou a abordagem restrita de risco, incapazes de conter a miséria, os conflitos intrafamiliares e as péssimas condições de saúde da população brasileira. Nesse sentido, Amarante afirma que ESF vem representar um investimento na "promoção da saúde e na defesa da vida, educando a comunidade e desenvolvendo práticas de pensar e lidar com a saúde" (2007, p.94). Para o mesmo autor, $80 \%$ dos casos de doenças poderiam ser resolvidos no âmbito da rede básica, com cuidados mais simples, privilegiando a escuta e o acolhimento dos sujeitos em atividades que aspirem ao reconhecimento da condição de sujeito e cidadão. 
Além dessas considerações, o conceito de promoção de saúde possui estreita relação com práticas que possibilitam ao grupo familiar, por exemplo, ampliar a sua rede de apoio diante de momentos críticos. Assim, a ação do psicólogo na ESF apresenta-se através de um retorno à base das relações afetivas e constitutivas do sujeito, em que a desinformação e a desorientação podem representar dois grandes pilares na fragmentação afetiva entre os membros e importantes pontos de origem de patologias. A atenção dispensada à saúde da família pelo psicólogo compreende também uma forma de prevenção contra os fatores que colaboram para o processo de adoecimento do grupo.

Visando a expandir a ESF, o Ministério da Saúde criou recentemente, em 2008, o Núcleo de Apoio à Saúde da Família NASF, que deve ser constituído por equipes compostas por profissionais de diferentes áreas de conhecimento, para atuarem com os profissionais das Equipes de Saúde da Família, compartilhando as práticas em saúde nos territórios sob responsabilidade das equipes de SF no qual o NASF está cadastrado (Brasil, 2008). O núcleo tem como objetivo ampliar as ações da atenção primária que, através da equipe multiprofissional, abre caminhos para diálogos necessários e urgentes a fim de melhor acolher e acompanhar os usuários. Reconhecendo a relevância de estudos e pesquisas sobre a dimensão psicológica do adoecer e de sua relação com os contextos social, cultural e familiar (Amarante, 2007; Cardoso, 2002, 2007; Mello Filho \& Burn, 2010; Lisboa, 2011), este trabalho ressalta e justifica a presença do psicólogo na equipe do NASF e na atenção básica, a partir das ações apresentadas neste relato de experiência.

\section{A contribuição dos estudiosos de família para a saúde}

Em 1962, a Psicologia passou a ser uma profissão regulamentada com trabalhos específicos que servem de base para ações especializadas, dentre elas, a de promoção de saúde. Com isso, a atenção dispensada aos estudos de caso, diagnósticos e psicoterapias ganhou ênfase e passou a ser coadjuvante e colaboradora de tratamentos de inúmeros pacientes (Dimenstein, 1998). Juntamente ao reconhecimento da Psicologia, estão trabalhos de terapeutas de família que, segundo FéresCarneiro (2008), há quase 40 anos existem no Brasil, com pesquisas e práticas que promovem articulações teóricas possíveis no atendimento às demandas contemporâneas. Os estudiosos e terapeutas de família vêm contribuindo com suas práticas para um melhor entendimento das formações, das transformações do grupo e dos efeitos destas no processo de subjetivação. A escuta da família realizada por um psicólogo em campo é capaz de facilitar a compreensão das demandas explícitas e subjacentes do sofrimento e, com isso, ampliar os sentidos do binômio saúde-doença para toda a equipe de saúde.

O predomínio da psicoterapia exercida por psicólogos em consultório particular, como nos casos dos psicoterapeutas de família, fazia com que ela ficasse descontextualizada das demandas sociais durante certo tempo, até que o surgimento de um novo cenário com atuações efetivas do profissional em ambulatórios sociais passou a proporcionar o atendimento ao alcance de todos. Essa prática vem contribuindo para que a população carente tenha acesso ao serviço de Psicologia que, desde a década de 1970, vem trabalhando para a inserção do psicólogo em instituições públicas, principalmente no campo da assistência pública à saúde (Dimenstein, 1998). De lá para cá, o número de psicólogos nessas instituições vem aumentando cada vez mais em todo o Brasil, apesar de numericamente ainda constituírem 
uma categoria pouco expressiva em relação ao quadro geral das profissões de saúde. Além disso, o mesmo autor enfatiza ainda a necessidade de os psicólogos agirem junto a outros profissionais, em sintonia com o contexto social, contribuindo efetivamente para a melhoria das condições de saúde e da qualidade de vida da população.

Nesse ângulo, a Psicologia deve oferecer devolutivas de suas ações para outros profissionais e para a sociedade, e ter a prática inserida em um contexto sociocultural para poder exercer o seu papel social. A atuação do psicólogo na atenção básica, por isso, deve ampliar o objetivo de prevenção e de promoção de saúde, à medida que consegue visualizar, com o sujeito e o grupo familiar, caminhos que fomentam o sofrimento de todos ou de alguns. Nessa nova proposta de ação, o trabalho do psicólogo com famílias compreenderia uma escuta diferenciada e, ao mesmo tempo, interdisciplinar da saúde e da doença, de modo a deslocar a atenção individual do adoecimento e dos sintomas para a dimensão intersubjetiva, que é atravessada por uma história e por uma forma particular de convivência entre os membros. Sendo assim, através do trabalho da Psicologia clínica e social, constrói-se uma multiplicidade de ações que possam responder velhas e novas demandas subjetivas da doença e do sujeito.

\section{O conceito de saúde e de família no cenário da atenção básica}

O conceito de saúde definido pela Organização Mundial da Saúde é muito divulgado no meio acadêmico, e compreende um estado de bem-estar físico, mental e social, e não meramente a ausência de doença ou um estado silencioso dos órgãos. A partir dessas últimas concepções, a doença só podia ser compreendida através de dois ângulos: ou era consequência de uma agressão ao organismo, com duração limitada, e que, cessada, deixava sequelas ou não, ou traduzia-se por uma desarmonia orgânica resultante de problemas anatômicos ou de desarranjos funcionais (Romano, 1999).

A atual definição de saúde da OMS visa, contudo, a uma perfeição inatingível, em que o termo bem-estar favorece amplas e subjetivas interpretações. Além disso, o sentimento de bem-estar tem relação com características da personalidade, o que o torna bastante singular em sua forma de compreensão. Outro ponto mostra que a condição de saúde, como ausência da doença, certamente não é contestada, o que leva a se confundir com o silêncio dos órgãos, pelo menos não inteiramente, visto que um órgão pode ser doente e não fazer barulho algum, ou ainda fazer muito barulho sem que se esteja doente. Dessa forma, é extremamente difícil conceituar a saúde, pois a doença, através das diversas maneiras de manifestação e concepção, coloca a posteriori a questão da saúde.

Segundo observações de Almeida Filho (2000), a partir das diversas faces da doença, esta se revela na prática clínica de forma paradoxal. Isso quer dizer que portadores de doenças que sofreram agravos e sequelas ou estão incapacitados parcialmente ou são reconhecidos como pessoas com vida produtiva tanto social como profissionalmente. Tais sujeitos não demonstram sinais de comprometimento ou sofrimento nos laços construídos, e tampouco são afetados em suas funções cotidianas, ao contrário de outros sujeitos acometidos, que se apresentam incapacitados, limitados e sofridos sem, todavia, possuir qualquer evidência clínica. As observações em campo influenciam os profissionais a terem novos olhares para a construção de práticas clínicas e sociais, visando a uma compreensão do processo de adoecimento a partir das 
A família possui uma visão de mundo particular, com códigos de comportamento, papéis de gênero, conceito de tempo e de espaço, linguagem, história, mitos e rituais que comunicam um sofrimento psíquico e físico (Helman, 2003/2007). condições de saúde, pois, como diz Scliar (2007), a saúde e a doença terão diferentes representações com base na época, no lugar, na classe social e nos valores culturais de uma comunidade. Tanto quanto a saúde, a doença terá representações variadas, e, ao longo dos séculos, tem sido vista como um processo transmissível comum e próprio da espécie humana. Partindo do pressuposto individual e transmissível, a doença revelará, incondicionalmente, o que há de melhor e de pior no ser humano (Almeida Filho, 2000; Sontag, 1984), pois abre caminho para uma introspecção de todos os acontecimentos mais significativos e se atreve a apontar aqueles deixados à deriva durante a trajetória de vida do sujeito e da família.

Assim, a saúde, do ponto de vista subjetivo, estará, antes de tudo, ligada às ideias do próprio sujeito, que ele constrói e a que se habitua, e serão elas mesmas criadas em função de suas influências familiares, culturais e da representação do próprio corpo e de seu funcionamento. Se a saúde também é um valor subjetivo, os conflitos pessoais se refletirão à sua altura, já que ela é portadora da integridade da pessoa. As inquietudes sobre a saúde se traduzirão sempre e preferencialmente pelas inquietudes da doença (Almeida Filho, 2000).

A Psicologia, ao questionar a relação entre os recursos materiais e o bem-estar subjetivo, enriqueceu o conceito de qualidade de vida. Isso possibilitou que pesquisas estudassem dados concretos como habitação, saúde, lazer, trabalho e família, sem deixar de lado dados relacionados ao grau de satisfação e de relevância de cada uma dessas áreas, surgindo assim a qualidade associada à percepção da satisfação com a vida e às suas condições e estabelecendo a relação entre as expectativas do indivíduo e o seu nível de satisfação (Flanagan, 1978).
No campo da qualidade de vida e da saúde, portanto, qual seria a função da família? A família constitui uma unidade social básica e presente em qualquer comunidade. Do ponto de vista psíquico, a dinâmica da família determina a definição e a conservação das diferenças humanas, dando forma objetiva aos papéis distintos, mas mutuamente vinculados. As suas normas de funcionamento dependem da cultura (Féres-Carneiro, 1996), e é por ela que há, também, a construção dos diferenciais de normal e de patológico na relação do sujeito com a saúde e com a doença. A família possui uma visão de mundo particular, com códigos de comportamento, papéis de gênero, conceito de tempo e de espaço, linguagem, história, mitos e rituais que comunicam um sofrimento psíquico e físico (Helman, 2003/2007).

Ainda que sejam encontradas várias abordagens teóricas sobre a Psicologia e os estudos de família, é preciso reconhecer que tais campos oferecem um diálogo enriquecedor com a saúde, uma vez que compreendem também uma via eficaz no tratamento e na cura de enfermidades mentais e somáticas. As diretrizes culturais e o funcionamento psicológico implícito e explícito de um grupo familiar orientam as pessoas na sua maneira de ver o mundo, em como comportar-se diante dele e em experimentá-lo emocionalmente. As respostas a esse movimento inter-relacional podem mostrar as importantes influências sobre o estado de saúde e de doença dos sujeitos do grupo.

\section{Método}

Este trabalho apresenta um relato de experiência de pesquisa que foi desenvolvida em parceria com uma universidade pública federal e com uma unidade básica de saúde da mesma cidade. O trabalho de campo da pesquisa compreendeu uma investigação sobre a saúde da família do ponto de vista de 
sua história, psicodinâmica e inter-relação. A ação ocorreu nos domicílios de famílias assistidas pela equipe de Saúde da Família da região leste da cidade mineira. Como na cidade não havia psicólogo no programa de saúde da família, no primeiro momento, solicitamos uma autorização da Secretaria Municipal de Saúde para a inclusão desse profissional. Posteriormente, foi realizado contato com a chefia da equipe de Saúde da Família da unidade para apresentação das atividades a serem realizadas em duas etapas: a primeira, com a equipe de saúde, e a segunda, com as famílias em domicílio.

Nos primeiros momentos da pesquisa, foram propostas reuniões semanais com a equipe de saúde, composta por agentes de saúde, médicos, enfermeiros e assistente social. Essas reuniões tinham a finalidade de discussão e de encaminhamento das famílias a serem entrevistadas pelos pesquisadores. Os agentes de saúde e o assistente social coordenaram os encaminhamentos. Nesses encontros, foram levantados os perfis das famílias e as doenças dos membros do grupo. Participaram do processo de investigação em domicílio um psicólogo-pesquisador e nove estagiários do curso de Psicologia da universidade ao longo de três anos e meio. A seleção dessas famílias foi feita seguindo os critérios de a) serem usuários do programa do bairro, b) possuírem um ou mais de um membro com algum tipo de doença, c) apresentarem pelo menos duas gerações durante as entrevistas (pais e filhos, avós e netos) e d) coabitarem em um mesmo terreno ou casa.

A segunda etapa do procedimento da pesquisa consistiu na realização de quatro entrevistas domiciliares, uma em cada semana. Na primeira semana, o agente de saúde agendava um encontro com a família selecionada, a fim de que os pesquisadores, a proposta da pesquisa e o Consentimento Livre e Esclarecido fossem apresentados aos membros. Nas semanas seguintes, foram realizadas três entrevistas gravadas, depois da assinatura do consentimento por todos os membros presentes durante os encontros. Nesses momentos, procurávamos acolher as demandas familiares, escutando as queixas, as histórias de vida e a dinâmica do grupo de maneira a respeitar os seus limites de ambiente físico, a sua cultura e as suas condições socioeconômicas.

Ao tratar de uma pesquisa na área da Psicologia, o procedimento se caracterizou por uma investigação qualitativa, e segue, dentre alguns paradigmas e interpretações citados por outros autores sobre método qualitativo, as concepções de Turato (2003). O autor mostra que, no cerne de um método qualitativo, estão os sentidos e as significações dos fenômenos ou objetos estudados, cujas questões nunca antes percebidas podem ser apontadas preliminarmente por dados quantitativos. Assim, a investigação qualitativa da saúde da família influenciou o procedimento não só da pesquisa como também da equipe de saúde e dos dados que coletou. Isso quer dizer que as entrevistas realizadas pelo psicólogo e pelos estagiários no ambiente domiciliar permitiram compreender alguns impasses gerados durante o atendimento e o tratamento desses usuários.

Nas reuniões semanais com a equipe de saúde da unidade básica, foram realizadas entrevistas de aculturação (Turato, 2003), a fim de que os agentes de saúde e o assistente social pudessem indicar famílias para a construção da pequena amostragem da população a ser investigada. Outro objetivo das entrevistas foi observar a concepção da 
equipe sobre as famílias assistidas por ela. Nas casas das famílias, foram utilizadas duas principais técnicas de investigação qualitativa: a observação livre e ampla do espaço físico, dos membros e dos entrevistadores, e as entrevistas semidirigidas. A observação livre foi realizada pelos estagiários durante todos os encontros, e, a posteriori, houve a confecção de um relatório com base em um roteiro pré-estabelecido. As entrevistas semidirigidas se dividiram em dois momentos: no primeiro, houve o levantamento de dados socioeconômicos e culturais sem nenhuma gravação, e, no segundo momento, ocorreram três encontros seguidos, quando houve gravação das entrevistas. Existia um roteiro, que constava de perguntas abertas, de esclarecimentos e de aprofundamento, baseadas em itens construídos durante a entrevista-piloto (Nicolacci-da-Costa, 2007).

\section{Resultados e discussão}

Durante os anos da pesquisa, foram validados 14 casos de família por assinarem o Termo de Consentimento Livre e Esclarecido. Na unidade de Atenção Primária à Saúde, havia quatro equipes de saúde da família, sendo que cada equipe atendia em torno de 400 famílias; os casos entrevistados representaram um percentual de $3,5 \%$ dos atendimentos realizados por uma equipe de saúde. Das 53 pessoas entrevistadas, a maioria era adulta com doenças crônicas, como a hipertensão e o diabetes. No entanto, verificamos que $13,2 \%$ dessas doenças estavam associadas a um histórico de uso crônico de álcool. Do ponto de vista psíquico, em relação à investigação sobre a história e a dinâmica dessas famílias, os depoimentos revelaram que o alcoolismo estava presente em 50\% dos casos de violência. Os dados sobre abuso sexual e suspeita de abuso apareceram em
$45 \%$, e os de histórias de violência física e psicológica corresponderam a 50\%, sendo que a maioria ocorria entre casais.

À medida que realizávamos as entrevistas, percebíamos que esse procedimento viabilizava o relato de segredos das histórias familiares. De acordo com a análise de discurso (Nicolacci-da-Costa, 2007), realizada a partir dos depoimentos coletados, em cinco casos, houve revelação de abuso sexual, relação incestuosa e tentativa de suicídio. Nove famílias denunciaram situações conflituosas e até violentas que também aconteciam naquele momento. $\mathrm{O}$ depoimento de três membros de famílias diferentes sobre a sua história de vida indicava situações vivenciadas que os mesmos relacionavam em diferentes momentos das entrevistas com a sua condição atual de saúde. A seguir, os depoimentos de adultos doentes sobre suas histórias de vida familiar:

Família 1 - ...Que, quando a gente era criança, a gente passava muita dificuldade ...Meu pai é... era muito doente, ficou dois anos em cima duma cama, morreu cedo. Então a minha mãe, ela bebia bastante, e isso complicava, né (membro adulto com diabetes).

Família 2 - Meu pai bebia demais. Ih! Bebia muito (...). Quando ele dormia pras estradas é que ele dava sossego para minha mãe; quando ele chegava em casa, ele queria bater né nóis, bater nela. Precisava nóis pulava tudo pela janela, ... e nois dormia as vez debaixo de chuva, debaixo da moita de bambu (membro adulto com hipertensão).

Família 3 - A minha mãe foi ótima! O meu pai não tem como dizer. Ele era tão lindo! E além de ser tão lindo... Ele levar nois pra cama... Ele levava nois pra cama e nois dormia com ele... Pegava e levava (membro adulto com enfisema e história de alcoolismo). 
Em relação ao trabalho com a equipe, a presença do psicólogo trouxe esclarecimentos sobre a dinâmica e os conflitos de famílias, colaborando na compreensão das falhas dos tratamentos estabelecidos, como a falta de entendimento entre os membros no tratamento do doente, o uso excessivo de remédios por realizarem uma peregrinação em vários médicos, o não cumprimento da prescrição do tratamento passado pelo médico da família, a interrupção do uso da medicação sem comunicar a equipe e o abandono ou resistência do próprio tratamento pelo usuário por problemas familiares e por concepções culturais e religiosas. Também foram observados fatos nunca antes revelados à equipe, como histórias de violência física e psicológica, de abuso sexual e de uso crônico de álcool, que vieram à tona e puderam explicar parte dos problemas enfrentados pelos médicos, enfermeiros e agentes de saúde na continuidade da assistência a certos usuários dessas famílias entrevistadas.

A boa aceitação das famílias e a troca de informações com os profissionais contribuíram para que mudanças no tratamento ocorressem em 25\% delas. Com as intervenções adequadas e de acordo com o contexto da escuta pelo psicólogo, 15\% procuraram seguir o tratamento sugerido pelo médico sem continuar com a automedicação ou com interrupções por contra própria. Em discussão com a equipe, foram observadas novas maneiras de conduzir o tratamento, sendo uma delas a revisão de algumas medicações pelo médico para interromper o uso excessivo e indiscriminado pelo usuário. Outro ponto relevante foi o fato de que alguns usuários de cinco famílias mudaram a sua aparência, apresentando-se com maior cuidado, asseio e preocupação com uma atividade de trabalho e atividade física, visando a melhor qualidade de vida.
Acreditamos que a história e as relações familiares compreendem importantes coadjuvantes, tanto no tratamento de doenças como no processo de adoecimento dos sujeitos. Por isso, reforçamos os trabalhos de Bittencourt e Matheus (2006), Cardoso (2002) e Chazan (2004), mostrando que a presença do psicólogo, principalmente no domicílio das famílias assistidas pelo programa, viabiliza melhor compreensão de suas relações e história por outros profissionais. A experiência de estar em domicílio acolhendo as queixas e as demandas dos familiares trouxe benefícios aos próprios usuários e maior esclarecimento à equipe de saúde no que diz respeito aos estados psicológicos e ao uso da terapêutica medicamentosa. Assim, constatamos, juntamente a Amarante (2007), Chazan (2004), Lisboa e Féres-Carneiro (2005) e Mello Filho e Burn (2004), que a dinâmica familiar influencia na compreensão e no tratamento do sujeito, uma vez que a doença também possui uma trama subjetiva e intersubjetiva em suas representações e relações.

As informações subjetivas sobre a dinâmica familiar puderam servir de base para novas estratégias de ação dos profissionais, como as realizadas pelo assistente social, ao procurar acompanhamentos específicos em órgãos competentes para os casos mais graves de violência. Também houve maior esclarecimento nos diálogos estabelecidos com a CAPS regional e com algumas escolas nos casos de depressão crônica e grave e de problemas de aprendizagem em duas famílias com crianças. Aos agentes, essas informações ajudaram na construção dos limites subjetivos em seus trabalhos, a serem respeitados durante as intervenções. Como os profissionais são, geralmente, vizinhos das famílias assistidas, eles puderam refletir sobre novas estratégias nas relações com as mesmas. Em relação aos médicos e enfermeiros, essas 
informações ajudaram na reconstrução de novos diagnósticos, antes falseados pela depressão latente de alguns usuários e pelo uso crônico de álcool por outros.

\section{Conclusões}

Diferentemente de outros trabalhos desenvolvidos pelos psicólogos nas equipes de saúde, a escuta da dinâmica familiar facilitou o conhecimento da história de vida desses membros por outros profissionais, colaborando para que o tratamento e a promoção estivessem mais ao alcance de todos os envolvidos no programa. O trabalho interdisciplinar e o acolhimento do psicólogo na atenção básica permitem ampliar diálogos e visualizar caminhos para a saúde do sujeito, uma vez compreendidos os aspectos culturais e psicodinâmicos da família.

Mesmo que ainda não seja uma realidade em todas as regiões brasileiras, a partir desta experiência, confirmamos que a integralização da ação do psicólogo aos trabalhos de atenção básica à saúde vem ao encontro dos princípios gerais da Política Nacional de Atenção Básica e da promoção da saúde (Brasil, 2006, 2008), ao mesmo tempo em que aponta resultados possíveis e satisfatórios na promoção de saúde e no tratamento de doenças. A avaliação técnica e interdisciplinar das perturbações e conflitos subjetivos pode revelar certa relação com o desenvolvimento de doenças em alguns usuários. Acrescentamos ainda que, além da atenção básica, o trabalho do psicólogo pode ser desenvolvido no NASF de forma diversa da postura assistencialista do tratamento convencional.

Conforme nosso relato de experiência sobre o procedimento da pesquisa, podemos dizer que esse trabalho influenciou a ação da equipe de saúde, uma vez que a escuta dos problemas familiares pelo psicólogo contribuiu para um redirecionamento do tratamento e do cuidado com alguns membros doentes. Isso se apresentou através de segredos da história familiar nunca antes revelados para a equipe de saúde, o que indicava certo comprometimento da família com outros segmentos sociais, inclusive com atendimentos e tratamentos realizados por médicos. Assim, pudemos considerar que a revelação de segredos, conflitos e violência tumultuava os atendimentos na UAPS.

Reafirmamos que as equipes de saúde da família podem encontrar certa dificuldade em seu trabalho de acompanhamento do usuário por lidarem, muitas vezes, com uma dinâmica familiar conflituosa e por desconhecerem os complexos movimentos subjetivos do grupo. Diante disso, podemos dizer que a não inserção do psicólogo na maioria dos programas de saúde básica contribui para que os desencontros entre os aspectos subjetivos e objetivos envolvidos no tratamento de doenças e na promoção de saúde se acentuem. Como citado na introdução, muitos trabalhos têm sido publicados nessa direção, reforçando a ação do psicólogo como um caminho interdisciplinar na busca de melhor qualidade na atenção primária à saúde do usuário. Contudo, são poucas as ações dirigidas para a família em seu domicílio pelos psicólogos, e verificam-se avanços tímidos na prática efetiva do trabalho técnico e, ao mesmo tempo, interdisciplinar com resultados satisfatórios.

Hoje acredita-se que a promoção de saúde esteja ao alcance de todos, mas nem sempre será seguida por todos, porquanto os conflitos familiares se fazem presentes em casos específicos. Em consequência disso, a prevenção de doenças a partir da escuta de 
famílias representa um desafio para todos os profissionais, porque o domicílio é o lugar de encubação e de fomento de inúmeros conflitos e situações de risco. Mesmo assim, entendemos que a escuta e o acolhimento em domicílio representam ações eficazes para a atenção básica e propomos que o psicólogo seja efetivamente incluído nesse processo. Isso representa um desafio maior para os profissionais de saúde, pois demanda uma articulação maior de trabalho com outros profissionais e redes sociais, como escolas, pastorais, centros recreativos, etc. E ainda se torna mais desafiador quando o trabalho se dirige às famílias em situação de risco.
A contribuição deste relato mostra que os dados coletados durante o procedimento desta pesquisa podem influenciar uma equipe de saúde na construção de novas ações às famílias assistidas, uma vez que a organização e a formação destas apontam diferentes sentidos na relação do sujeito com a saúde e com a doença, cujas particularidades de comportamento, cultura, linguagem, história, mito e rituais próprios podem contribuir tanto para o sofrimento psíquico e físico quanto para o bem-estar de seus membros. 


\section{Aline Vilhena Lisboa}

Psicóloga, Terapeuta de família e de casal, Doutora em Psicologia Clínica pela PUC Rio de Janeiro e Pesquisadora do Núcleo Interdisciplinar de Investigação em Psicossomática e Organizações da Universidade Federal de Juiz de Fora, Minas Gerais, MG - Brasil.

E-mail: alinevlisboa@ig.com.br

\section{Alessandra Larcher dos Santos}

Graduada em Psicologia pela Universidade Federal de Juiz de Fora e Membro do NUIPSO - Universidade Federal de Juiz de Fora, Minas Gerais, MG - Brasil.

E-mail: alelarcher@yahoo.com.br

Fernanda Anselmo Bassoli

Graduada em Psicologia pela Universidade Federal de Juiz de Fora e Membro do NUIPSO - Universidade Federal de Juiz de Fora, Minas Gerais, MG - Brasil.

E-mail: nanda.bassoli@yahoo.com.br

\section{Nadia Delgado Paiva}

Graduada em Psicologia pela Universidade Federal de Juiz de Fora e Membro do NUIPSO - Universidade Federal de Juiz de Fora, Minas Gerais, MG - Brasil.

E-mail: nadinhadp@yahoo.com.br

\section{Tatiana Campos Fernandes}

Graduada em Psicologia pela Universidade Federal de Juiz de Fora e Membro do NUIPSO - Universidade Federal de Juiz de Fora, Minas Gerais, MG - Brasil.

E-mail: tatipsijf@hotmail.com

\section{Endereço para envio de correspondência:}

Rua José Cristiano Ney, 552 - Riviera - Macaé, Rio de Janeiro, RJ - Brasil. CEP 27935-370

Recebido 28/5/2010, 1a Reformulação 4/7/2011, Aprovado 12/8/2011. 


\section{Referências}

Almeida-Filho, N. de. (2000). O conceito de saúde: pontocego da epidemiologia? Revista Brasileira de Epidemiologia, 3(13), 4-20.

Amarante, P. (2007). Saúde mental e atenção psicossocial. Rio de Janeiro: Fiocruz.

Brasil. Presidência da República e Senado Federal. (1990). Lei n. 8080, de 19 de setembro de 1990. Brasília: Autor.

Brasil. Ministério da Saúde. (1994). Programa de Saúde da Família. Brasília: COSAC.

Brasil. Ministério da Saúde. (1997). Programas de Agentes Comunitários e Saúde da Família: PACS/PSF. Portaria n. 1886 18 de dezembro de 1997. Brasília: Ministério da Saúde. Recuperado em 28 de junho de 2011 de www.saudeprev. com.br.

Brasil. Ministério da Saúde. (2006). Política Nacional de Promoção de Saúde/MS, SAS. Brasília: Ministério da Saúde. 60 p. Recuperado em 28 de fevereiro de 2008 de http:// portal.saúde.gov.br/portal/arquivos/pdf/pactovolume7.pdf.

Brasil. Ministério da Saúde. (2008). Departamento de Atenção Básica - PSF - Saúde da Família. Brasília: Ministério da Saúde. Recuperado em 26 de abril de 2010 de http://dab.saude. gov.br/nasf.php.

Bittencourt, R. A. do A., \& Mateus, M. L. F. (2006). Possibilidades de atuação do psicólogo no Programa Saúde da Família: a experiência de Bonito-MS. Psicologia: Ciência e Profissão, 26(2). Recuperado em 17 de agosto de 2009 de http:// pepsic.bvsalud.org/scielo.php?script=sci_serial\&pid $=1414$ $9893 \& n r m=i s o \& r e p=\& \operatorname{lng}=p t$

Cardoso, C. L. (2002). A inserção do psicólogo no Programa Saúde da Família. Psicologia: Ciência e Profissão, 22(1). Recuperado em 4 de novembro de 2009 de_http://pepsic. bvsalud.org/scielo.php?script $=$ sci_serial\&pid $=1414$ $9893 \& n r m=$ iso $\&$ rep $=\& \operatorname{lng}=p t$

Cardoso, C. L. (2007). Um estudo fenomenológico sobre a vivência de família: com a palavra, a comunidade. Tese de doutorado. Departamento de Pós-Graduação em Psicologia - PUC-Rio, Rio de Janeiro.

Castiel, L. D. (1994). O estresse na pesquisa biomédica e epidemiológica: as limitações do modelo de risco no estudo do processo saúde-doença. In L. D. Castiel, $O$ buraco e o avestruz: a singularidade do adoecer humano (Cap. 4, pp. 127-203). Campinas, SP: Papirus.

Chazan, L. F. (2004). Trabalhando com as famílias na atenção primária. In J. de Mello Filho, \& M. Burn (Orgs.), Família e doença (Cap. 6, pp. 111-21). São Paulo: Casa do Psicólogo.

Dimenstein, M. D. B. (1998). O psicólogo nas unidades básicas de saúde: desafios para a formação e atuação profissionais. Estudos de Psicologia, 3(1), 53-81.

Féres-Carneiro, T. (1996). Família: diagnóstico e terapia. Rio de Janeiro: Vozes.

Féres-Carneiro, T. (2008). Articulando diferentes abordagens na formação de terapeutas de família. In Anais da jornada de psicanálise dos vínculos: família e casal (pp. 73-84). Sociedade Brasileira de Psicanálise do Rio de Janeiro.

Flanagan, J. C. (1978). A research approach to improving our quality of life. American Psychologist, 33, 138-289.

Helman, C. G. (2007). Cultura, saúde e doença. Porto Alegre: Artmed (Trabalho original publicado em 2003).

Lisboa, A. V., \& Féres-Carneiro, T. (2005). Quando o adoecimento assombra e une o grupo familiar. Pulsional Revista de Psicanálise, 18(184), 40-48.

Lisboa, A. V. (2011). A história familiar no processo de adoecimento somático: a violência em destaque. Tese de doutorado. Departamento de Pós-graduação em Psicologia - PUC-Rio. Rio Janeiro.

Mello Filho, J. de, \& Burn, M. (2004). Doença e família. São Paulo: Casa do Psicólogo.

Mello Filho, J. de, \& Burn, M. (2010). Psicossomática hoje. (2a ed.) Porto Alegre: Artmed.

Nicolacci-da-Costa, A. M. (2007). O campo da pesquisa qualitativa e o método de explicitação do discurso subjacente (MEDS). Psicologia: Reflexão e Crítica, 1(20), 65-73.

Romano, B. W. (1999). Princípios para a prática clínica do psicólogo em hospitais (Cap. 2 e 6, pp. 36-44 e 83-100). São Paulo: Casa do Psicólogo.

Santana, M. L., \& Carmagnami, M. I. (2001). Programa saúde da família no Brasil: um enfoque sobre seus pressupostos básicos, operacionalização e vantagens. Revista Saúde e Sociedade, 10(1), 33-53.

Scliar, M. (2007). História do conceito de saúde. Physis Revista de Saúde Coletiva, 17(1), 29-41.

Sontag, S. (1984). A doença como metáfora. Rio de Janeiro: Graal.

Turato, E. R. (2003). Tratado da metodologia da pesquisa clínicoqualitativa (2a ed.). Rio de Janeiro: Vozes.

Viana, A . L. D., \& Dal Poz, M. R. (2005). A reforma do sistema de saúde no Brasil e o Programa de Saúde da Família. Physis Revista de Saúde Coletiva, 8(2),11-48. 